\title{
DIRECT INJECTION OF B. TYPHOSUS INTO THE GALLBLADDER
}

\author{
T. D. BECKWITH
}

\author{
From the Department of Bacteriology and Experimental Pathology, University of \\ Caltfornia, Berkeley
}

The work of Rous and McMaster ${ }^{1}$ following less successful attempts of Rost, ${ }^{2}$ Werelius ${ }^{3}$ and Mann $^{4}$ indicates that the wall of the gallbladder has a definite part in concentrating bile. This function is so active that when estimates are based on pigment readings, reduction in volume of cystic bile amounts approximately to nine-tenths in 22 hours. These observations have drawn attention to an activity hitherto not well recognized. Meltzer ${ }^{5}$ has indicated that the gallbladder is under nerve control, which leads one to suspect that this function may be under central direction. As the walls of this organ are richly supplied with lymph channels, it seems likely that this intense activity may be related to lymph circulation.

The work cited causes one to consider the possibility of infection or of intoxication to the general system by deleterious bodies or compounds within the cystic bile. The older idea that presence of $B$. typhosus within the gallbladder in a typhoid carrier is due to direct invasion of the bacilli by way of the common and cystic ducts from the duodenum no longer seems tenable. However, there is still strong reason to believe that this may be the path of invasion for Endameba dysenteriae and for certain parasites. One may conceive that a foreign toxin-producing body within the bile may be able to produce a generalized condition in the body as the wall of the gallbladder has been demonstrated to comprise an active, permeable and concentrating mechanism.

With this possibility in mind, it was attempted to learn whether the introduction of $\mathrm{B}$. typhosus within the gallbladder directly is followed by the appearance of bacilli and of agglutinins in the circulation.

The strain of B. typhosus used in these experiments is known as "No. 3" in this laboratory and is the same as that used in a large

Received for publication, Aug. 1, 1922.

* Aided by grant from University of California Board of Research.

1 Jour. Exper. Med., 1921, 34, pp. 47 and 75.

2 Mitt. a. d. Grenzgeb. d. Med. t. Chir., 1913, 26, p. 710.

s Surg., Gynec. \& Obst,, 1917, 25, p. 520.

- New Orleans Med. \& Surg. Jour., 1918-19, 71, p. 80.

5 Am. Jour. Med. Sc., 1917, 153, p. 469. 
portion of the work reported in previous communications from this department. It was cultivated on $6 \%$ rabbit blood agar according to the method outlined by Gay and Claypole, ${ }^{6}$ that is in tubes of $18 \mathrm{~mm}$. internal diameter with slopes as long as possible without wetting the cotton plugs. Inoctlations from a broth culture were made over the entire surface and this was followed by incubation at $37 \mathrm{C}$. for 20-24 hours. The resulting growth was then suspended by careful shaking in salt solution to the amount of $10 \mathrm{cc}$. Injections were made of 0.5 $\mathrm{c} \mathrm{c}$ of this suspension, equal to $1 / 20$ slant.

Rabbits were selected weighing from 2,800 to $3,500 \mathrm{gm}$., and apparently healthy. Preliminary fecal examinations to insure absence of protozoa or other parasites were not made.

Direct injection into the gallbladder was made as follows: The animal, stretched on a Latapie operating board, was prepared by shaving the abdomen, after which the surface was painted with tincture of iodin. A few moments later this was washed off with cresol solution. The fur coat about the shaved area was also wet down well with cresol, and the animal was covered entirely with a sterile sheet having a circular window over the site of incision.

The incision, generally 1 inch long, is made just at one side of the median line with its anterior end at the base of the sternum. Ordinarily by use of a retractor and sponges, the gallbladder located in its cleft is revealed without difficulty. In case it is distended it should be evacuated partially by the application of gentle pressure from the finger. By smooth, blunt forceps, the bladder may be drawn forward gently and injection carried out by an assistant. The needle ordinarily used is No. 27 gage, $1 / 2$ inch long. The fine needle must be inserted through the outer aspect of the gallblatder wall where the blood vessels are not so numerous. On withdrawal of the needle it is wise to watch for a moment in order to make certain that there is no leakage or bleeding after the abduction has ceased. The incision through the abdominal wall is then sutured, skin clips are applied, together with dressing of zinc oxide ointment, sterile cotton and collodion. Using these precautions, together with daily inspection, the loss of animals will be negligible.

By this technic, 16 animals were inoculated directly into the gallbladder, while as a check 9 received the same dosage in the posterior ear vein. Of the 16 first mentioned, 8 were bled regularly for agglutinin titration, while the other 8 were not tested so systematically.

- Arch. Int. Med., 1913, 12, p. 613. 
Tables 1 and 2 give the agglutinin titers of rabbits with intracystic injection as compared with those treated intravenously. Titers were read after 2 hours' incubation at $37 \mathrm{C}$. followed by a night, about 18 hours, in the icebox. Only such tubes as showed complete clarity were considered. The antigen was living bacilli from a 24-hour slant suspended in sterile salt solution.

TABLE 1

Aggivtinin Titers of Rabits Injected Directly into the Galladadder with 1/20 Slant Culture of B. TYPhosus

\begin{tabular}{|c|c|c|c|c|c|c|c|c|}
\hline Rabbits & 3 Days & 5 Days & 7 Days & 11 Days & 14 Days & 21 Days & 28 Days & 35 Days \\
\hline 804 & 10 & 40 & 80 & 80 & 20 & 80 & 40 & 10 \\
\hline 633 & $>5$ & 40 & 40 & 40 & 40 & 40 & 40 & 20 \\
\hline 684 & $>5$ & 160 & 640 & 160 & 160 & 160 & 80 & 80 \\
\hline 614 & 5 & 160 & 80 & 80 & 80 & 40 & 40 & 40 \\
\hline 661 & 5 & 160 & 160 & 160 & 160 & 80 & 80 & 40 \\
\hline 620 & 5 & 80 & 160 & 80 & 40 & 40 & 20 & 20 \\
\hline 680 & $>5$ & 80 & 80 & 80 & 80 & 40 & 20 & 20 \\
\hline 644 & 10 & 10 & 20 & 160 & 80 & 80 & 20 & 10 \\
\hline 427 & .. & $\ldots$ & 320 & & 160 & & & \\
\hline 895 & .. & .. & $\ldots$ & 160 & 80 & & & \\
\hline 679 & $\cdots$ & 40 & & 20 & & & & \\
\hline 870 & $\therefore$ & $\cdots$ & 160 & $\ldots$ & 80 & & & \\
\hline 829 & . & $\cdots$ & 10 & $\ldots$ & 20 & & & \\
\hline 898 & . & 80 & & $\ldots$ & 40 & & & \\
\hline $\begin{array}{l}876 \\
817\end{array}$ & & 40 & 40 & $\begin{array}{r}20 \\
1000\end{array}$ & Dead & & & \\
\hline 018 & & 40 & 100 & $10 \mathrm{~d}$ & Dead & & & \\
\hline
\end{tabular}

$>$ signifies "less than."

TABLE 2

Agglutinin Titers of Rabatts Injected Intrayenouszy with $1 / 20$ Slant Culture OF B. TYPHOSLS

\begin{tabular}{|c|c|c|c|c|c|c|c|c|}
\hline Rabbits & 3 Days & 5 Days & 7 Days & 11 Days & 14 Days & 21 Days & 28 Days & 35 Days \\
\hline $\begin{array}{l}826 \\
652 \\
674 \\
802 \\
698 \\
365 \\
175 \\
366 \\
501\end{array}$ & $\begin{array}{r}20 \\
10 \\
10 \\
20 \\
10 \\
5 \\
0 \\
0 \\
\ldots\end{array}$ & $\begin{array}{r}\ldots \\
\ldots \\
\ldots \\
\ldots \\
320 \\
20 \\
320 \\
5\end{array}$ & $\begin{array}{r}320 \\
80 \\
2560 \\
320 \\
80 \\
320 \\
80 \\
320 \\
20\end{array}$ & $\begin{array}{r}80 \\
80 \\
320 \\
320 \\
40 \\
160 \\
40 \\
640 \\
40\end{array}$ & $\begin{array}{r}320 \\
80 \\
640 \\
320 \\
80 \\
180 \\
20 \\
80 \\
40\end{array}$ & $\begin{array}{c}80 \\
40 \\
320 \\
80 \\
80 \\
160 \\
80 \\
160 \\
\text { Dead }\end{array}$ & $\begin{array}{c}40 \\
40 \\
160 \\
40 \\
80 \\
\text { Dead } \\
\text { Dead } \\
\text { Dead }\end{array}$ & $\begin{array}{l}40 \\
20 \\
80 \\
20 \\
40\end{array}$ \\
\hline
\end{tabular}

From these experiments, it is evident that the placing of B. typhosus within the gallbladder is followed by prompt mobilization of antibodies. The resulting titer is not so high as that following intravenous injection of a comparable amount, but nevertheless it is unmistakable.

Following this series it was determined to ascertain whether injection of dead typhoid bacilli into the gallbladder is followed by agglutinin production. The same technic as that described was used. The sus- 
pension had been heated to $56 \mathrm{C}$. for 45 minutes and then tested for sterility by cultural methods. The volume injected was the same as before. The results are shown in table 3 .

It is evident that implantation of dead typhoid bacilli within the gallbladder stimulates the appearance of agglutinins in the circulation, promptly and vigorously.

The results seem to indicate that the bacilli must pass through the cystic wall since it is unlikely that the mere presence of $B$. typhosus within the cystic bile itself can stimulate such heavy agglutinin production in the circulation. Moreover, it is stated by Gay ${ }^{7}$ that only approximately two-thirds of chronic human gallbladder carriers of typhoid give an agglutinin reaction, which of itself probably indicates that the assumption noted is correct. It is a well-known anatomic condition that although the blood circulation in the gallbladder wall is not copious compared to certain other tissues, the lymphatic channels

TABLE 3

Agglutinin Titers of Rabits Injected Directly into the Gallbladder with $1 / 20$ Slant Culture of B. typhosus Kified by Heat

\begin{tabular}{|c|c|c|c|c|c|c|c|c|}
\hline Rabbits & 3 Days & 5. Days & i Days & 11 Days & 14 Days & 21 Days & 28 Irays & 35. Days \\
\hline $\begin{array}{l}628 \\
612 \\
667\end{array}$ & $\begin{array}{c}5 \\
10 \\
10\end{array}$ & $\begin{array}{r}40 \\
40 \\
1280\end{array}$ & $\begin{array}{l}160 \\
160 \\
640\end{array}$ & $\begin{array}{r}20 \\
40 \\
160\end{array}$ & $\begin{array}{r}40 \\
40 \\
160\end{array}$ & $\begin{array}{r}40 \\
20 \\
160\end{array}$ & $\begin{array}{l}80 \\
40 \\
80\end{array}$ & $\begin{array}{r}40 \\
40 \\
160\end{array}$ \\
\hline
\end{tabular}

are numerous. Thus it is probable that if there be dissemination of the bacterial forms after passing through the bladder wall, the lymph is instrumental in part at least.

Since it seems likely that particulate matter such as typhoid bacilli may pass through the wall of the gallbladder, it was decided to study whether this is possible. The method was first to inject a large quantity of typhoid bacilli directly into the cystic bile through the bladder wall and then by bleeding at intervals to search for the bacilli in the circulation. Following this, after a few hours the animal was killed and a bacteriological examination of various tissues made. This examination was carried out as follows: After chloroforming, the body was opened; portions of the organs were removed with sterile instruments, macerated in sterile salt solution with mortar and pestle, after which approximately $1 \mathrm{cc}$ of the resulting suspension was placed in plain broth tubes. Ordinary routine of cultivation on solid mediums followed by

7 Typhoid Fever Considered as a Problem of Scientitic Medicine, 1918, p. 129. 
aggiutination tests with known antityphoid serum was used for recognition of bacterial growths. Descriptions of these experiments follow:

Exper. 1.-Male rabbit $300,3,500 \mathrm{gm}$., injected by laparotomy with $0.5 \mathrm{c} \mathrm{c}$ suspesion containing 1/6 slant of a 24-hour growth of $B$. typhosus on rabbit blood agar. The animal was bled $1 / 2$ hour after injection and $0.5 \mathrm{c} c$ of the fresh blood placed in plain broth. Bleedings were made hourly thereafter until death by chloroforming at $5 \frac{1}{2}$ hours. At necropsy cultural examinations were made from heart blood, bile, urine, duodenal content, liver, kidney, spleen, lung and bone marrow. B. typhosus was recovered from liver, spleen, lung, bile and intestinal content but not in any other preparations.

Exper. 2.- Male rabbit $350,2,800 \mathrm{gm}$., underwent laparotomy with direct injection of $0.5 \mathrm{c} \mathrm{c}$ containing $1 / 4$ of a 24 -hour slant culture of $\mathrm{B}$. typhosus. One-half $\mathrm{c} c$ of blood was removed from the ear vein $1 / 4$ hour after injection and placed in plain broth. Like bleedings were made hourly thereafter until time of necropsy following chloroform at $5 \frac{1}{4}$ hours. Cultural preparations were made from heart blood, bile, urine, duodenal contents, liver, spleen, kidney, lung and bone marrow. B. typhosus was obtained from bile and duodenal contents, liver, spleen, kidney and lung. All other preparations were negative.

Exper. 3.-Male rabbit $374,3,500 \mathrm{gm}$, received $0.5 \mathrm{cc}$ suspension of $1 / 4$ of a 24-hour rabbit blood slant culture of $\mathrm{B}$. typhosus directly into the gallbladder. Following this $0.5 \mathrm{cc}$ blood was removed from the ear vein $1 / 4$ hour later and thereafter hourly to the time of necropsy following death by chloroform, at $6 \frac{1 / 4}{4}$ hours. These samples were placed immediately in plain broth. At final dissection cultural examinations were made of heart blood, bile, urine, duodenal content, liver, spleen, kidney, bone marrow and lung. B. typhosus was recovered from the bile, duodenal content and spleen. All other cultures were negative.

It is evident that $B$. typhosus after intracystic injection may pass promptly through the epithelial lining of the bladder and be disseminated to various organs of the body. The lymph would seem to be the medium for carriage, as the bacillus was not isolated from the peripheral blood stream during any of the 3 experiments. It should be noted, however, that during the earlier stages of this work and while proper technic was being elaborated, 3 small rabbits of 1,500 to $1,800 \mathrm{gm}$. weight were injected directly into the gallbladder. These died between the tenth and eighteenth hour after operation. Rigor mortis had set in by the time of necropsy, but no more exact statement can be made regarding the period between death and examination. B. typhosus was isolated from the heart blood of each one. In these dead animals, therefore, the organism was present within the circulation but we have no assurance that its presence was not due to postmortem migration.

Microscopic examination by paraffin section stained by hematoxylin - cosin after Zenker or Kaiserling was made of the gallbladder of animals having undergone daparotomy and intracystic injection. The 
results are similar to those of Findlay and Buchanan, ${ }^{8}$ Bindseil, ${ }^{8}$ Goebel ${ }^{10}$ and Messerchmidt, ${ }^{11}$ with human material and those of Meyer, Neilson and Feusier ${ }^{12}$ with animals. Two weeks had elapsed between the injection and the examination. Sections showed necrosis accompanied by desquamation of the epithelium, especially on the outer folds of the villi, although it was present to less marked degree at their base. This change was evident both in the body and in the neck of the bladder. Areas of intense infiltration were present in the villi and to a less degree in inner portions of the tunica propria. Numerous capillaries were blocked by masses of erythrocytes. Edema was marked and the wall thickened. Although Meyer, Neilson and Feusier ${ }^{12}$ state that rabbits injected with $B$. typhosus into the gallbladder showed no stripping of epithelium, it will be noted that those of the series described here did. It is very possible that the time factor explains this difference. The picture was the same whether with intravenous or intracystic injection.

\section{SUMMARY}

Injection of B. typhosus directly into the gallbladder of the rabbit is followed by prompt appearance of agglutinins within the circulation. This response is stimulated by dead as well as by living organisms. Typhoid bacilli implanted within the gallbladder pass through the lining epithelium and appear shortly in other organs, such as the spleen, liver, lung, and kidney, but they were not isolated from the peripheral circulation. It seems likely that lymph is at least partially responsible for this distribution. Migration of B. typhosus through the epithelium into the tunica is attended after appropriate lapse of time by the formations of lesions which are characteristic of those found in the typhoid carrier.

\footnotetext{
8 Glasgow Med. Jour., 1906, 65, p. 177.

- Ztschr. f. Hyg. a. Infektionskr., 1913, 74, p. 369.

10 Ibid., 1914,78 , p. 555 .

11 Ibid., 1913, 75, p. 411.

12 Jour. Infect. Dis., 1921, 28, p. 76.
} 